\title{
PERAN PEREMPUAN DALAM MENGHADAPI BENCANA DI INDONESIA
}

\author{
Oleh: \\ Hastuti \\ Jurusan Pendidikan Geografi FIS UNY \\ hastuti@uny.ac.id
}

\begin{abstract}
Abstrak
Penduduk perempuan di Indonesia hampir separuh dari jumlah seluruh penduduk yakni setiap 100 perempuan terdapat 101 penduduk laki-laki (BPS, 2015). Komposisi penduduk itu dihadapkan dengan kondisi wilayah Indonesia yang rawan bencana. Bencana terus melanda muka bumi ini terutama di Indonesia berupa bencana alam maupun bencana sosial. Bencana melanda dengan menimbulkan kerugian harta benda bahkan mengancam keberlangsungan kehidupan dengan korban jiwa. Perempuan merupakan kelompok yang rentan ketika terjadi bencana. Upaya mengatasi bencana terus dikaji melalui kajian ilmiah, penelitian, maupun regulasi agar dapat ditekan dampak negatif yang meluas akibat bencana. Peran serta perempuan dalam menghadapi bencana mulai disadari sedemikian penting sehingga perempuan diharapkan dapat ikut mengurangi resiko bencana. Perempuan mulai dilibatkan dalam mitigasi bencana mulai dari pemulihan, rehabilitasi, sampai rekontruksi pasca bencana. Peningkatan peran perempuan dalam menghadapi bencana dilakukan melalui pendidikan, pelatihan agar perempuan memiliki pengetahuan dan kesadaran, serta keterampilan perempuan ketika menghadapi bencana. Dampak negatif ketika terjadi bencana diharapkan dapat ditekan melalui peningkatan peran perempuan dalam mengadapi bencana
\end{abstract}

Kata kunci: perempuan, bencana

\begin{abstract}
Female population in Indonesia reaches almost half of the total population, that is, there are 101 males every 100 females (BPS, 2015). Instead of having this composition of population, Indonesia is prone to disasters. Disasters continue to happen in this earth especially in Indonesia in the form of natural and social disasters. Disasters cause the loss of property and even endangers the lives of the victims. Women include a vulnerable group when disasters occur. The efforts to overcome the disasters continue to be reviewed through scientific study, research, and regulation in order that the widespread of its negative impacts can be reduced. The participation of women in dealing with disaster is now being realized so crucial that women are expected to help reduce the risk of disaster. Women begin to be involved in disaster mitigation ranging from restoration, rehabilitation to post-disaster reconstruction. Increasing the role of women to deal with disasters is performed through education, training for women to have knowledge, awareness, as well as skills when facing disasters. The negative impacts of disaster is expected to be reduced through the increasing role of women in facing disasters.
\end{abstract}

Keywords: women, disasters 


\section{PENDAHULUAN}

Berdasar data Susenas 2014 dan 2015, Badan Pusat Statistik (BPS) merilis jumlah penduduk Indonesia adalah sebesar 254,9 juta jiwa. Dari data tersebut, rinciannya adalah penduduk laki-laki berjumlah 128,1 juta jiwa dan perempuan berjumlah 126,8 juta jiwa. Perempuan merupakan kelompok masyarakat yang rentan ketika terjadi bencana. Jumlah penduduk perempuan yang hampir separuh dari jumlah penduduk Indonesia menjadi aspek penting yang seharusnya mendapat perhatian dalam menghadapi bencana. Perempuan relatif rentan ketika terjadi bencana, oleh karena itu meningkatkan peran serta perempuan dalam menghadapi bencana merupakan variabel penting untuk menekan kerugian sebagai dampak dari bencana.

Pendidikan tentang resiko bencana dan keselamatan merupakan prioritas utama untuk antisipasi bencana. Pengintegrasian informasi tentang resiko bencana ke dalam kehidupan sehari-hari merupakan langkah yang diharapkan mampu mengurangi resiko bencana yang tidak diinginkan. Perempuan seharusnya dikenalkan dengan lingkungan tempat tinggal mereka agar mampu memahami dinamika alam. Pemahaman terhadap dinamika alam ini menjadi prasyarat utama untuk penyelamatan terhadap resiko bencana. Guna mencapai ini diharapkan peran perempuan dapat dilibatkan dalam menghadapi bencana agar perempuan mampu mempertahankan diri dan keluarganya dari resiko bencana.

Indonesia terletak pada pertemuan tiga lempeng dunia yang masih aktif. Posisi demikian harus disadari bukan hanya sebagai berkah dengan deretan kegunungapian aktif yang melahirkan kesuburan tetapi rangkaian bencana pun dapat terjadi sewaktu-waktu di Indonessia. Menurut catatan sejarah tiga peristiwa alam yang mampu mempengaruhi perubahan iklim global pernah terjadi di Indonesia yakni meletusnya gunung api purba hingga terbentuknya danau Toba, meletusnya Krakatau, dan Tambora (banaspatigladiator.blogspot.com/2010/11/gunung-meletus-terhebat-sepanjang.html).

Bencana banyak melanda Indonesia baik berupa bencana karena alam seperti gunung api meletus, gempa bumi, puting beliung maupun bencana karena kekeliruan pengelolaan alam oleh manusia seperti bencana banjir, tanah longsor, pemanasan global, efek rumah kaca, dan kebakaran hutan. Ketika pemanasan global / global warming menjadi ancaman di masa depan, maka keberadaan negeri kepulauan ini cukup mengkhawatirkan. Ketika tinggi muka air laut meningkat karena terjadinya pencairan gletsyer menjadi ancaman bagi keberadaan negeri-negeri kepulauan termasuk Indonesia.

Anomali cuaca akhir-akhir ini sering terjadi sehingga banyak menimbulkan masalah mulai kekeringan ketika El Nino lebih panjang dan banjir terjadi dimana-mana ketika La Nina melaanda lebih dari biasanya. Fenomena banjir dan tanah longsor menjadi fenomena yang sering terjadi dengan meningkatnya curuh hujan dhadapkan pada penggunaan lahan yang tidak sesuai peruntukannya. Fenomena bencana ini telah menimbulkan kerugian harta benda bahkan peristiwa banjir dan tanah longsor bandang telah banyak memakan korban jiwa. BBC Indonesia (20 Juni,, 2016), peristiwa tanah longsor di Jawa Tengah Juni 2016 telah memakan korban jiwa 45 orang dan hilang 15 orang. Kemarau basah di Indonesia 2016 telah menyebabkan terjadinya banjir bandang di Garut September 2016 telah merenggut 33 korban Jiwa (Republika OL, 25 September 2016). 


\section{PEREMPUAN DAN BENCANA}

Indonesia memiliki wilayah dimana terdapat pertemuan lempeng dunia yang aktif sehingga pergerakan lempeng tersebut menimbulkan efek gempa bumi, tsunami, dan gunung berapi aktif. Kondisi ini diperparah oleh perilaku masyarakat yang kurang peduli terhadap keberadaan daya dukung lingkungan sehingga terjadi banjir, tanah longsor, kekeringan, polusi air, polusi udara, polusi tanah. Rangkaian bencana yang merugikan kelangsungan hidup masyarakat Indonesia. Sempurna sudah ancaman bencana di Indonesia yang terjadi karena wilayah Indonesia sebagai pertemuan lempeng aktif dunia ditambah pengrusakan alam karena perilaku masyarakatnya yang dapat menyebabkan terjadinya bencana alam.

Kehilangan sumberdaya ekonomi, kehilangan harta benda merupakan kerugian akibat bencana. Penderitaan akibat bencana tersebut perempuan merupakan kelompok masyarakat yang paling menderita. Perempuan paling menderita ketika terjadi bencana karena tugas domestik yang harus dipikul mereka harus menanggung anggota rumah tangga lain yang rentan ketika terjadi bencana yakni anak-anak, kelompok lanjut usia dan kelompok difabel.

Beberapa wilayah di Indonesia dihadapkan dengan persoalan yang dapat memicu terjadinya kemiskinan secara mendadak yakni terjadinya bencana. Bencana kekeringan, banjir, gunung meletus, gempa bumi, tanah longsor, kebakaran hutan dan lahan merupakan ancaman bagi sebagian wiyah di muka bumi. Rendahnya kualitas hidup karena derita kemiskinan menjadikan kelompok miskin terutama perempuan menjadi rentan terhadap serangan beberapa penyakit.

Ironisnya perempuan mengalami penderitaan yang lebih berat akibat bencana dan penanganan bencana, bahkan sebagai akibat perbedaan status gender telah meminggirkan perempuan sehingga memiliki posisi tawar rendah. Bencana menjadikan perempuan semakin rentan kemiskinan. Peningkatan jumlah perempuan sebagai kepala rumahtangga, setelah kehilangan pencari nafkah utama dan kehilangan sumber pendapatan, rumah tangga dengan kepala rumahtangga perempuan sangat rentan kemiskinan. Perempuan ketika berumahtangga dalam struktur masyarakat di Indonesia ditempatkan sebagai ibu rumahtangga yang banyak menyelesaikan pekerjaan domestik bukan diposisikan sebagai pencari nafkah. Wahidah Rustam (2015), bahwa perempuan merupakan kelompok yang paling rentan ketika terjadi bencana.

Perubahan iklim memiliki dampak yang dirasakan langsung oleh perempuan. Dalam rentang waktu lima bulan, dari Januari hingga Mei 2015 telah terjadi 881 bencana alam di berbagai wilayah di Indonesia. Terdapat keterkaitan yang erat antara bencana alam dan situasi ekonomi perempuan. Ketika bencana alam terjadi, banjir misalnya, maka perempuan petani juga perempuan nelayan akan kehilangan sumber ekonomi mereka. Jadi perubahan iklim sangat berpengaruh terhadap persoalan ekonomi sosial perempuan. 
Secara struktural bencana telah banyak menyebabkan perempuan menjadi miskin, disamping itu perempuan harus mengalami marjinalisasi dalam penanganan bencana. Perempuan dikonstruksi sebagai kelompok tersubordinasi oleh laki-laki sehingga perempuan harus menderita kesulitan untuk akses terhadap informasi tak terkecuali ketika terjadi bencana sampai pada tahap mitigasi bencana.

Perempuan memiliki keterbatasan akses terhadap sumberdaya seperti jaringan sosial, transportasi, informasi, keterampilan, kontrol sumberdaya alam dan ekonomi, mobilitas individu, tempat tinggal dan pekerjaan. Keterbatasan akses berdampak pada proses mitigasi dan pemulihan akibat bencana sehingga marjinalisasi ini telah menyebabkan perempuan harus menanggung penderitaan yang lebih berat ketika tertimpa bencana. Perempuan memiliki tugas-tugas domestik di rumah tangga. Tugas domestik seperti mengurus anak, orangtua yang berusia lanjut, dan anggota keluarga yang memiliki keterbatasan fisik akibat bencana. Perempuan tidak memiliki kebebasan berpindah tempat untuk mencari pekerjaan setelah mengalami bencana, sementara lakilaki secara leluasa dapat berpindah tempat dan meninggalkan rumah tangga tanpa terikat tugas domestik.

\section{RANGKAIAN BENCANA TERUS MENGANCAM INDONESIA}

Faktor alam Indonesia sebagai sesar aktif merupakan kawasan yang menyimpan potensi bencana. Bencana sulit dihindarkan, bencana akibat pengaruh dari pergeseran lempeng bumi (gempa tektonik, gunung meletus) maupun perubahan iklim (badai, topan, kekeringan) dapat menimbulkan kerugian fatal dalam kehidupan manusia. Bencana karena perilaku manusia keliru dalam pengelolaan sumberdaya yang menyebabkan banjir, tanah longsor, kekeringan, polusi (air, udara, dan tanah) merupakan bencana yang banyak terjadi pula di Indonesia. Indonesia merupakan pertemuan lempeng dunia yang aktif sehingga pergerakan lempeng masih terus terjadi yang dapat menimbulkan efek gempa bumi dan tsunami. Indonesia negeri yang memiliki gunung berapi aktif terbanyak di dunia, ancaman letusan gunung berapi dapat terjadi setiap saat mulai dari Sumatera, Jawa, Nusa Tenggara sampai Sulawesi.

Sutopo Purwo Nugroho (2016) menyebutkan bahwa bencana banjir, bencana sedimen, gempa bumi, dan tsunami merupakan empat karakter bencana yang dominan terjadi di Indonesia. Dari 1.681 kejadian bencana menyebabkan 259 orang tewas, 1,23 juta mengungsi, 25.192 unit rumah rusak (5.180 rusak berat, 3.760 rusak sedang, 16.252 rusak ringan), 498 unit fasum rusak. Lebih dari 95\% merupakan bencana hidrometeorologi. Puting beliung, longsor dan banjir paling dominan, longsor adalah jenis bencana paling mematikan 157 orang tewas. Secara eksplisit mengenai distribusi bencana yang terjadi pada tahun 2015 dapat dilihat pada Tabel 1 berikut 
Tabel 1 Distribusi Bencana di Indonesia Tahun 2015

\begin{tabular}{|c|c|c|c|c|c|c|c|c|c|c|}
\hline \multirow{4}{*}{ Jenis Bencana } & \multirow{4}{*}{$\begin{array}{l}\text { Jumlah } \\
\text { Kejadian }\end{array}$} & \multirow{3}{*}{$\begin{array}{l}\text { Meninggal } \\
8 \text { Hilang }\end{array}$} & \multirow{3}{*}{$\begin{array}{l}\text { Menderita \& } \\
\text { Mengungsi }\end{array}$} & \multicolumn{7}{|c|}{ Kerusakan } \\
\hline & & & & \multicolumn{4}{|c|}{ Rumah } & \multirow{2}{*}{$\begin{array}{l}\text { Fasillitas } \\
\text { Pendidikan }\end{array}$} & \multirow{2}{*}{$\begin{array}{c}\text { Fasilitas } \\
\text { Peribadatan }\end{array}$} & \multirow{2}{*}{$\begin{array}{l}\text { Fasilitas } \\
\text { Kesehatan }\end{array}$} \\
\hline & & & & Rusak Berat & $\begin{array}{l}\text { Rusak } \\
\text { Sedang }\end{array}$ & Rusak Ringan & Terendam & & & \\
\hline & & \multicolumn{2}{|c|}{ Jiwa } & \multicolumn{7}{|c|}{ Unit } \\
\hline Banjir & 492 & 39 & 841.505 & 657 & 260 & 2.425 & 176.031 & 221 & 58 & 16 \\
\hline Gempa Bumi & 27. & - & 17,382 & 2.024 & 547 & 3.107 & & 28 & 48 & 10 \\
\hline Kebakaran Hutan Dan Lahan & 45 & 24 & - & & & & & $\cdot$ & $\cdot$ & $\cdot$ \\
\hline Puting Beliung & 561 & 29 & 7.431 & 1.858 & 2578 & 9.856 & 81 & 46 & 34 & 6 \\
\hline Tanah Longsor & 501 & 157 & 25.924 & 508 & 299 & 636 & 286 & 10 & 10 & 1 \\
\hline
\end{tabular}

Sebagai termaktub dalam Lampiran Peraturan Menteri Dalam Negeri tentang Pedoman Umum Mitigasi Bencana (2016) tersirat bahwa Indonesia merupakan wilayah yang rawan bencana

Dilihat dari potensi bencana yang ada, Indonesia merupakan negara dengan potensi bahaya (hazard potency) yang sangat tinggi. Beberapa potensi tersebut antara lain adalah gempa bumi, tsunami, banjir, letusan gunung api, tanah longsor, angin ribut, kebakaran hutan dan lahan, letusan gunung api. Potensi bencana yang ada di Indonesia dapat dikelompokkan menjadi 2 kelompok utama, yaitu potensi bahaya utama (main hazard) dan potensi bahaya ikutan (collateral hazard). Potensi bahaya utama (main hazard potency) ini dapat dilihat antara lain pada peta potensi bencana gempa di Indonesia yang menunjukkan bahwa Indonesia adalah wilayah dengan zona-zona gempa yang rawan, peta potensi bencana tanah longsor, peta potensi bencana letusan gunung api, peta potensi bencana tsunami, peta potensi bencana banjir, dan lain-lain. Dari indikator-indikator di atas dapat disimpulkan bahwa Indonesia memiliki potensi bahaya utama (main hazard potency) yang tinggi. Hal ini tentunya sangat tidak menguntungkan bagi negara Indonesia.

Distribusi bencana di Indonesia tahun 2015 per propinsi dapat dilihat pada Gambar 1 di bawah ini 


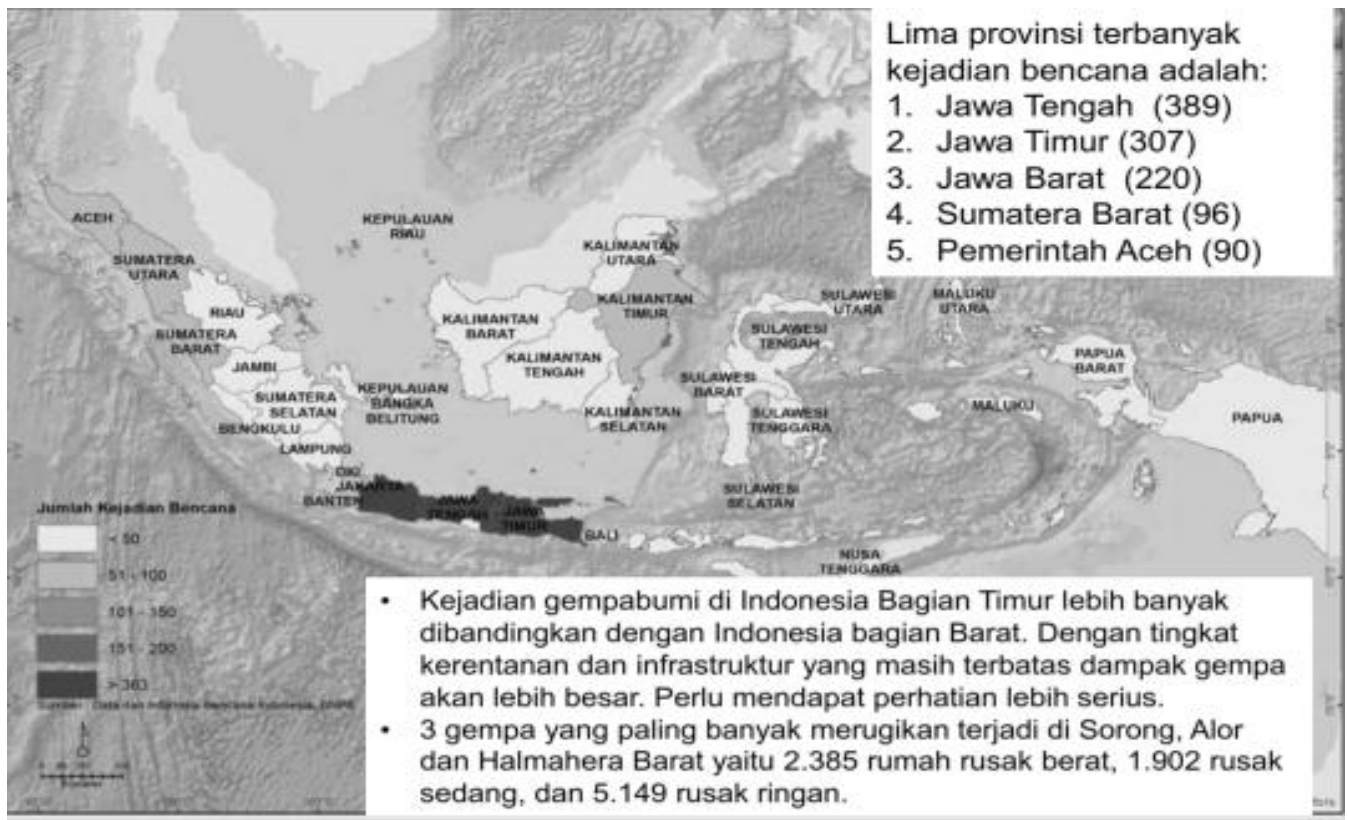

Gambar 1. Distribusi Bencana di Lima Propinsi di Indonesia

Sumber: BNPB, 2016

\section{PERAN PEREMPUAN DALAM MENGURANGI RISIKO BENCANA}

Perempuan memiliki peran strategis dalam menghadapi bencana agar resiko yang ditimbulkan akibat bencana dapat ditekan melalui upaya meningkatkan peran perempuan dalam mitigasi bencana. Untuk meningkatkan kemampuan perempuan dalam mengurangi risiko bencana dapat dilakukan melalui peningkatan :

1. Kesadaran perempuan dalam memahami situasi lingkungan dan ancaman bahaya

2. Pemahaman tentang kerentanan dan kemampuan untuk mengukur kapasitas yang dimiliki perempuan

3. Kemampuan untuk menilai risiko yang dihadapi perempuan sebagai individu, anggota keluarga dan masyarakat

4. Kemampuan untuk merencanakan dan melakukan tindakan untuk mengurangi risiko yang dimiliki baik melalui peningkatan kapasitas dan mengurangi kerentanan

5. Kemampuan perempuan untuk memantau, mengevaluasi dan menjamin keberlangsungan upaya pengurangan risiko sehingga dampak bencana dapat dikurangi atau dicegah

Dampak bencana yang melanda suatu wilayah memiliki karakter berbeda bergantung tingkat kesiapan, ketahanan, dan kapasitas untuk pemulihan. Kerentanan setelah terjadi bencana dapat berkepanjangan tanpa penanganan yang serius pasca bencana. Bencana tak jarang memusnahkan harapan dan masa depan mengingat banyaknya korban jiwa, musnahnya harta benda, lenyapnya sumber pendapatan, dan rusaknya sistem sosial di masyarakat. Ketika bencana melanda suatu wilayah dampak yang ditimbulkan bervariasi meliputi kerentanan sosial, merosotnya kesejahteraan, ancaman terhadap mata pencaharian dan ketahanan pangan, hilangnya perlindungan diri sendiri, 
hilangnya perlindungan sosial, menurunnya derajad kesehatan, hilangnya harta benda, kekacauan jaringan sosial dan kelembagaan (Omar D. Cardona, 2011). Kondisi demikian hanya akan dapat ditangani dengan baik apabila terjadi kesiapan masyarakat untuk menghadapi bencana. Mengenai strategi penyelamatan terhadap bencana secara terintegrasi dapat dilihat pada Gambar 2 berikut

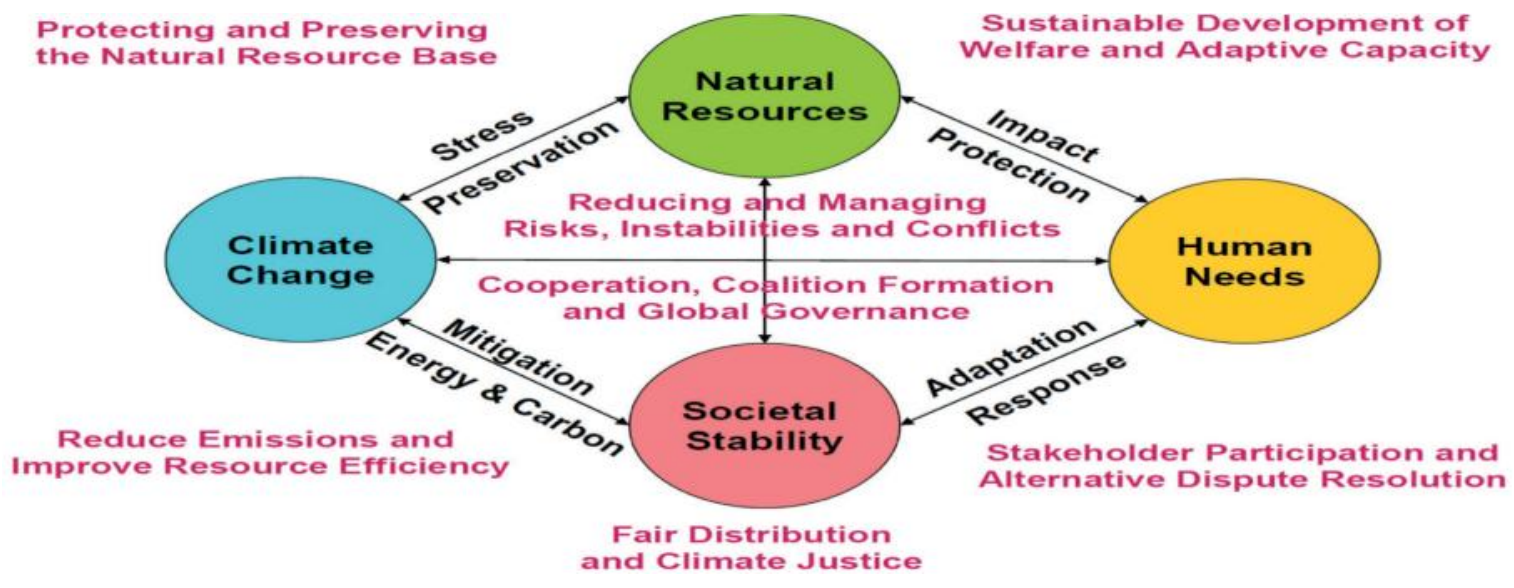

Gambar 2. Strategi Penyelamatan Terhadap Bencana Dengan Kerangka kerja Terintegrasi (Hans Günter Brauch et al., 2011)

Perencanaan dan pelaksanaan suatu kebijakan yang hanya sekedar untuk merespon persoalan jangka pendek bukan cara pemecahan masalah yang bijak. Kajian sejak dini mengenai bencana serta dampak yang terjadi, tahap evakuasi, dan pemulihan berkesinambungan diperlukan kesiapan masyarakat untuk dikondisikan siap menghadapi bencana. Perencanaan kebijakan terkait bencana diperlukan integrasi antar berbagai variabel meliputi alam, lingkungan, infrastruktur, sosial, politik, budaya, dan ekonomi. Penguatan masyarakat sangat diperlukan ketika menghadapi bencana mulai dari penguatan sosial, ekonomi, budaya, dengan terjaminnya ketersediaan pangan, sandang, kesehatan, dan tempat berlindung. Prosedur mitigasi bencana secara eksplisit diperlukan untuk melindungi masyarakat dan aset kehidupan sehingga dapat dijadikan tumpuan untuk melanjutkan kehidupan pasca bencana.

Sadisun (2006), prosedur mitigasi bencana hendaklah memperhatikan

1. Kehidupan / penyelamatan nyawa

2. Keamanan

3. Kesehatan

4. Perlindungan harta benda

5. Perlindungan lingkungan

6. Pengamanan fasilitas penting

7. Pengamanan fasilitas umum

8. Koordinasi antar institusi pemerintah 
Mengedepankan penyelamatan jiwa menjadi prioritas utama dalam menghadapi bencana. Perlindungan keamanan, kesehatan, penyediaan fasilitas dan infrastruktur untuk kelangsungan hidup seperti ketersediaan air bersih, dan keamanan pangan hendaklah menjadi prioritas setelah penyelamatan.

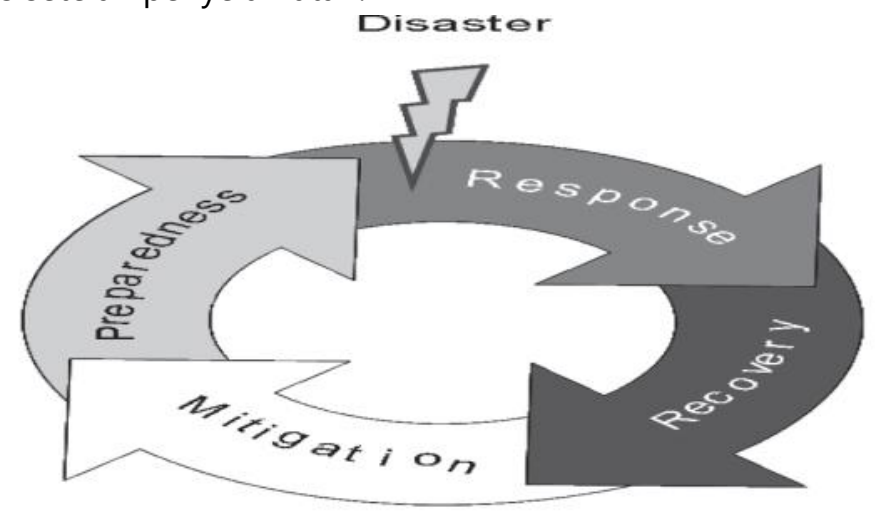

Gambar 3. Siklus Mitigasi Bencana oleh FEMA dalam Hans Günter Brauch et al., (2011)

Agar dampak yang ditimbulkan akibat bencana tidak berkepanjangan maka diperlukan langkah yang sigap mulai dari proses pemulihan, rehabilitasi, dan rekonstruksi

1. Proses pemulihan (recovery) kondisi lingkungan dan masyarakat yang terkena dampak/bencana, dengan memfungsikan kembali prasarana dan sarana pada keadaan semula, memperbaiki prasarana dan pelayanan dasar (jalan, listrik, air bersih, fasilitas kesehatan, fasilitas ekonomi, dan fungsi lingkungan).

2. Rehabilitasi (rehabilitation), yaitu upaya untuk membantu masyarakat memperbaiki rumahnya, fasilitas umum dan sosial penting, maupun menghidupkan kembali roda perekonomian dan fungsi lingkungan setelah bencana terjadi.

Rekonstruksi (reconstruction) merupakan upaya jangka menengah dan jangka panjang guna untuk mengembalikan kehidupan masyarakat pada kondisi yang sama atau lebih baik dari sebelumnya.

\section{PENUTUP}

Upaya mengatasi bencana terus dikaji melalui kajian ilmiah maupun regulasi agar dapat ditekan dampak dari bencana. Peran perempuan menjadi sangat penting saat ini mulai disadari dapat mengurangi resiko bencana dan memperkokoh ketahanan perempuan ketika harus menghadapi bencana. Perencanaan dan pelaksanaan suatu kebijakan yang hanya sekedar untuk merespon persoalan jangka pendek bukan cara pemecahan masalah yang bijak. Perencanaan kebijakan terkait bencana dituntut integrasi antar berbagai komponen meliputi alam, lingkungan, infrastruktur, sosial, politik, budaya, dan ekonomi. Penguatan peran perempuan sangat diperlukan ketika menghadapi bencana mulai dari penguatan sosial, ekonomi, dan budaya. Peran perempuan dalam mitigasi seharusnya ditingkatkan sehingga dapat menekan terjadinya kerentanan yang ditimbulkan akibat bencana seperti kelaparan, keterbatasan akses, kehilangan tempat tinggal, 
merosotnya kesehatan yang dapat memicu timbulnya konflik berkepanjangan pasca bencana.

\section{UCAPAN TERIMA KASIH}

Penulis mengucapkan terima kasih kepada berbagai pihak yang telah membantu dalam penyusunan tulisan ini, baik selama proses penelusuran pustaka, diskusi, maupun penulisan.

\section{DAFTAR PUSTAKA}

BBC Indonesia, 2016, Korban longsor Jateng 47 tewas dan 15 hilang, BBC Indonesia 20 Juni 2016

Hans Günter Brauch et al., 2011, Hexagon Series on Human and Environmental Security and Peace, ISSN:1865-5793 e-ISSN:1865-5807 Springer-Verlag Berlin Heidelberg

Jürgen Scheffran, 2011, Security Risks of Climate Change: Vulnerabilities, Threats, Conflicts and Strategies dalam Hans Günter Brauch et al., 2011, Hexagon Series on Human and Environmental Security and Peace ISSN: 1865-5793 e-ISSN: 1865-5807 SpringerVerlag Berlin Heidelberg

Omar D. Cardona, 2011, Disaster Risk and Vulnerability: Concepts and Measurement of Human and Environmental Insecurity, dalam Hans Günter Brauch et al., 2011, Hexagon Series on Human and Environmental Security and Peace ISSN: 1865-5793 e-ISSN: 1865-5807 Springer-Verlag Berlin Heidelberg

Lampiran Peraturan Menteri Dalam Negeri, 2006, Tentang Pedoman Umum Mitigasi Bencana di Indonesia. NOMOR : 33 TAHUN 2006 TANGGAL: 18 OKTOBER 2006

Republika On Line, 2016, 33 Korban Tewas Banjir Bandang Garut Ditemukan, Republika OL 25 September 2016

Sadisun, 2006. Peran dan Fungsi Standard Operational Procedure (SOP) dalam Mitigasi Bencana Alam, Pusat Mitigasi Bencana ITB, Bandung

Sutopo Purwo Nugroho, 2016. Badan Nasional Penanggulangan Bencana Evaluasi Penanggulangan Bencana 2015 Dan Prediksi Bencana 2016, BNPB 2016

Wahidah Rustam, 2015, Perempuan adalah Korban Terbesar dari Berbagai Bencana Yang Terjadi, Jurnal Perempuan 15 September 2015.

banaspatigladiator.blogspot.com/2010/11/gunung-meletus-terhebat-sepanjang.html 